\title{
COMPARATIVE STUDY BETWEEN DEXMEDETOMIDINE AND MAGNESIUM SULPHATE AS SEDATIVES IN AWAKE FIBEROPTIC INTUBATION IN CONTROLLED HYPERTENSIVE ADULT PATIENTS
}

\author{
By
}

\section{Mohamed Ali Mohamed Abd El-Aal, Gamal Farouk Mohamed, and Amr Soliman Hamrosh}

Anesthesiology and Intensive Care Department, Faculty of Medicine, Al-Azhar University

Corresponding Author: Mohamed Ali Mohamed Abd El-Aal

E-mail: dr_muhammed8632@yahoo.com

\begin{abstract}
Background: Flexible bronchoscopy has become the "gold standard" for managing the expected and unexpected difficult airway. Several drugs have been used to provide adequate sedation to optimize adequate fiberoptic intubation.

Objective: To compare the sedative effects of dexmedetomidine and magnesium sulphate during awake fiberoptic nasal intubation in controlled hypertensive adults undergoing elective surgeries.

Patients and methods: Sixty controlled hypertensive patients intubated using awake fiberoptic. They were divided into 2 equal groups: Patients received dexmedetomidine infusion at dose of $1 \mathrm{ug} / \mathrm{kg}$, and the other patients received magnesium sulphate at dose of $30 \mathrm{mg} / \mathrm{kg}$. Topicalization of airway was done using lidocaine "spray as you go technique". After completing the loading dose, Ramsay score was assessed before intubation. The 2 groups were compared according to Ramsay score, cough score, facial grimace and hemodynamic changes. This study was done at Al-Azhar University Hospitals after approval of the medical ethical committee, from May 2019 till November 2020.
\end{abstract}

Results: Ramsay score, cough score and facial grimace were favorable with less hemodynamic effects in dexmedetomidine group than magnesium group.

Conclusion: Dexmedetomidine was effective sedative agent for awake fiberoptic intubation in controlled hypertensive patients in comparison with magnesium sulphate.

Keywords: Awake fiberoptic intubation, dexmedetomidine, magnesium sulphate.

\section{INTRODUCTION}

Awake fiberoptic intubation is indicated for patients with expected difficult airways where ideal positioning for laryngoscopy is challenging to attain. Patients should be prepared prior to awake intubation. Preparation includes decrease of airway reflexes and proper sedation together with preservation of the open airway and sufficient ventilation (Tsukamoto et al., 2018).

Many drugs could be used to provide sufficient sedation prior to awake fibreoptic intubation, but with side effects such as respiratory depression (Mondal et al., 2015). 
Dexmedetomidine is a selective $\alpha 2$ adrenoceptors agonist. It initially results in hypertension accompanied by reflex bradycardia, that effect is followed by hypotension and bradycadia. It provides adequate sedation without respiratory compromise, so it can be used before awake fiberoptic intubation (Weerink et al., 2017).

Magnesium Sulphate is NMDA receptor blocker. It has analgesic, anticonvulsant and sedative effects. It inhibits release of catecholamine due to sympathetic stimulation. It antagonizes calcium and decreases release of histamine and acetylcholine. Also, it has cardiac and neurological protective effects (Hyun-Jung et al., 2020).

This study aimed to compare between dexmedetomidine and magnesium sulphate to provide good sedation before awake fiberoptic nasal intubation in controlled hypertensive patients.

\section{PATIENTS AND METHODS}

Sixty controlled hypertensive patients, scheduled for elective surgeries under general anesthesia were enrolled in this randomized prospective double-blind study after approval of the medical ethical committee at Al-Azhar University Hospitals, Department of Anesthesia, and after patients gave written consents. Information about the study were given by the patients in oral and written forms.

The study was performed from May 2019 till November 2020. Patients were divided into 2 equal groups according to airway assessment using El-Ganzouri score (Klimov et al., 2018), and were randomized according to computer generated randomization technique:
- Dexmedetomidine Group: Patients received a bolus dose of dexmedetomidine at $1 \mathrm{mcg} / \mathrm{kg}$ over $10 \mathrm{~min}$ in $100 \mathrm{~mL}$ normal saline followed by continuous infusion of dexmedetomidine at $0.5 \mathrm{mcg} / \mathrm{kg} / \mathrm{h}$ till intubation.

- Magnesium Group: Patients received magnesium sulphate IV $(30 \mathrm{mg} / \mathrm{kg}$ in $100 \mathrm{ml}$ of $0.9 \%$ normal saline) through $10 \mathrm{~min}$ followed by a maintenance dose $10 \mathrm{mg} / \mathrm{kg} / \mathrm{h}$ till intubation.

Inclusion criteria: Adult patients of both sexes with controlled hypertension aged 20-65 years, scheduled for elective surgeries necessitating endotracheal intubation with general anesthesia.

Exclusion criteria: Uncooperative patients with nasal pathology, ASA $\geq 3$, severe airway trauma, coagulopathy, patients with cardiac or respiratory diseases as COPD or emergency operation.

Evaluation and preparation: On the day before surgery evaluation carried out by history, examination and required investigations. The technique discussed with the patients and their cooperation. A venous cannula was inserted into the patient, a monitor connected. Patients premedicated with intramuscular atropine 0.5 $\mathrm{mg}$ and intravenous Famotidine $20 \mathrm{mg} 30$ minutes preoperatively, oxygen $(3 \mathrm{~L} / \mathrm{min})$ administered via the nasal cannula. Decongestant nasal drops were used as and both nostrils were filled with cotton swabs immersed in $2 \%$ lidocaine with adrenaline to anaesthetize the mucosa of the nose.

Technique of fiberoptic intubation: Fiberoptic intubation started once the 
Ramsay score $\geq 2$ by spray as you go technique, lidocaine $2 \%$ injected through the side port of the bronchoscope till visualization of the epiglottis. The fiberoptic bronchoscope positioned under the epiglottis to see the vocal cords, then anesthetized with $2 \mathrm{~mL}$ of lidocaine $2 \%$. After entering the trachea, the endotracheal tube advanced over the bronchoscope. Capnogram was connected and general anesthesia was inducted.

The following parameters were assessed: Sedation score assessed by Ramsay sedation scale, cough score, facial grimace score, duration of tracheal intubation, intubation attempts, oxygen saturation and hemodynamic response to intubation: (HR, MAP, SpO2) which assessed at four different time intervals (baseline, $3 \mathrm{~min}$ after sedation, after advancing the ETT through the nasopharynx and $3 \mathrm{~min}$ after endotracheal intubation).

Statistical analysis: Recorded data were analyzed using the statistical package for the social sciences, version 20.0 (SPSS Inc., Chicago, Illinois, USA). Quantitative data were expressed as mean \pm standard deviation (SD), median and interquartile range (IQR). Qualitative data were expressed as frequency and percentage. Ttest was used in order to compare proportions between two qualitative parameters. P-value <0.05 was considered significant.

\section{RESULTS}

There was no statistically significant difference between two groups regarding their demographic data (Table 1).

Table (1): Comparison between Dexmedetomidine Group and Magnesium Group according to demographic data

\begin{tabular}{|c|c|c|c|}
\hline Demographic data & $\begin{array}{l}\text { Dexmedetomidine } \\
\text { Group }(\mathbf{n}=30)\end{array}$ & $\begin{array}{c}\text { Magnesium } \\
\text { Group }(n=30)\end{array}$ & p-value \\
\hline \multicolumn{4}{|l|}{ Age (years) } \\
\hline Mean \pm SD & $44.83 \pm 4.14$ & $44.50 \pm 3.60$ & \multirow{2}{*}{0.740} \\
\hline Range & $38-55$ & $38-51$ & \\
\hline \multicolumn{4}{|l|}{ Sex } \\
\hline Female & $13(43.3 \%)$ & $14(46.7 \%)$ & \multirow{2}{*}{0.795} \\
\hline Male & $17(56.7 \%)$ & $16(53.3 \%)$ & \\
\hline
\end{tabular}

There was a statistically significant increase of median in dexmedetomidine group compared to magnesium group according to Ramsay score (Table 2). 
Table (2): Comparison between Dexmedetomidine Group and Magnesium Group according to Ramsay sedation score

\begin{tabular}{|c|c|c|c|}
\hline $\begin{array}{ll}\text { Ramsay score } & \text { Groups } \\
\end{array}$ & $\begin{array}{l}\text { Dexmedetomidine } \\
\text { Group }(n=30)\end{array}$ & $\begin{array}{c}\text { Magnesium } \\
\text { Group }(\mathbf{n = 3 0})\end{array}$ & p-value \\
\hline 1 & $0(0.0 \%)$ & $21(70.0 \%)$ & \multirow{4}{*}{$<0.001$} \\
\hline 2 & $2(6.7 \%)$ & $9(30.0 \%)$ & \\
\hline 3 & $18(60.0 \%)$ & $0(0.0 \%)$ & \\
\hline 4 & $10(33.3 \%)$ & $0(0.0 \%)$ & \\
\hline Median $(I Q R)$ & $3(1)$ & $1(1)$ & \multirow{2}{*}{$<0.001$} \\
\hline Range & $2-4$ & $1-2$ & \\
\hline
\end{tabular}

There was a statistically significant decrease of mean in dexmedetomidine group compared to magnesium group according to mean arterial blood pressure at $3 \mathrm{~m}$ after sedation, after advancement ETT and at $3 \mathrm{~m}$ after intubation (Table 3).

Table (3): Comparison between Dexmedetomidine Group and Magnesium Group according to mean arterial blood pressure

\begin{tabular}{|c|c|c|c|}
\hline $\begin{array}{l}\text { Mean } \\
\begin{array}{l}\text { arterial blood } \\
\text { pressure (mmHg) }\end{array}\end{array}$ & $\begin{array}{l}\text { Dexmedetomidine } \\
\text { Group }(\mathbf{n}=\mathbf{3 0})\end{array}$ & $\begin{array}{c}\text { Magnesium } \\
\text { Group }(\mathbf{n}=\mathbf{3 0})\end{array}$ & p-value \\
\hline \multicolumn{4}{|l|}{ Baseline } \\
\hline Mean \pm SD & $93.13 \pm 3.55$ & $93.27 \pm 2.91$ & \multirow{2}{*}{0.874} \\
\hline Range & $85-99$ & $85-98$ & \\
\hline \multicolumn{4}{|l|}{ At $3 \mathrm{~m}$ after sedation } \\
\hline Mean \pm SD & $80.20 \pm 1.61$ & $85.53 \pm 2.11$ & \multirow{2}{*}{$<0.001$} \\
\hline Range & $76-89$ & $82-89$ & \\
\hline \multicolumn{4}{|l|}{ After advancement ETT } \\
\hline Mean \pm SD & $78.90 \pm 1.86$ & $86.57 \pm 1.72$ & \multirow{2}{*}{$<0.001$} \\
\hline Range & $74-82$ & $84-89$ & \\
\hline \multicolumn{4}{|l|}{ At $3 m$ after intubation } \\
\hline Mean \pm SD & $72.43 \pm 2.13$ & $84.47 \pm 2.26$ & \multirow{2}{*}{$<0.001$} \\
\hline Range & $70-78$ & $80-89$ & \\
\hline
\end{tabular}

There was statistically significant decrease of mean in dexmedetomidine group compared to magnesium group according to heart rate at $3 \mathrm{~m}$ after sedation, after advancement ETT and at $3 \mathrm{~m}$ after intubation (Table 4). 
Table (4): Comparison between Dexmedetomidine Group and Magnesium Group according to heart rate

\begin{tabular}{|c|c|c|c|}
\hline $\begin{array}{ll}\text { Heart rate } & \text { Groups } \\
\end{array}$ & $\begin{array}{l}\text { Dexmedetomidine } \\
\text { Group }(n=30)\end{array}$ & $\begin{array}{c}\text { Magnesium } \\
\text { Group }(n=30)\end{array}$ & p-value \\
\hline \multicolumn{4}{|l|}{ Baseline } \\
\hline Mean \pm SD & $81.70 \pm 4.27$ & $82.13 \pm 5.91$ & \multirow{2}{*}{0.746} \\
\hline Range & $75-90$ & $70-90$ & \\
\hline \multicolumn{4}{|l|}{ At $3 \mathrm{~m}$ after sedation } \\
\hline Mean \pm SD & $72.33 \pm 2.11$ & $77.53 \pm 4.38$ & \multirow{2}{*}{$<0.001$} \\
\hline Range & $70-78$ & $70-88$ & \\
\hline \multicolumn{4}{|l|}{ After advancement ETT } \\
\hline Mean \pm SD & $70.10 \pm 0.92$ & $88.47 \pm 3.48$ & \multirow{2}{*}{$<0.001$} \\
\hline Range & $69-73$ & $84-96$ & \\
\hline \multicolumn{4}{|l|}{ At $3 m$ after intubation } \\
\hline Mean \pm SD & $68.90 \pm 0.96$ & $76.37 \pm 3.08$ & \multirow{2}{*}{$<0.001$} \\
\hline Range & $67-71$ & $70-83$ & \\
\hline
\end{tabular}

There was a statistically significant decrease of median in dexmedetomidine group compared to magnesium group according to cough score (Table 5).

Table (5): Comparison between Dexmedetomidine Group and Magnesium Group according to cough score

\begin{tabular}{|c|c|c|c|}
\hline Cough score $\quad$ Groups & $\begin{array}{l}\text { Dexmedetomidine } \\
\text { Group }(n=30)\end{array}$ & $\begin{array}{c}\text { Magnesium } \\
\text { Group }(n=30)\end{array}$ & p-value \\
\hline None & $6(20.0 \%)$ & $1(3.3 \%)$ & \multirow{4}{*}{$<0.002$} \\
\hline One gag or cough only & $20(66.7 \%)$ & $11(36.7 \%)$ & \\
\hline $\begin{array}{l}>1 \text { gag or cough, but acceptable } \\
\text { conditions }\end{array}$ & $4(13.3 \%)$ & $13(43.3 \%)$ & \\
\hline Unacceptable conditions & $0(0.0 \%)$ & $5(16.7 \%)$ & \\
\hline Median $(I Q R)$ & $2(0)$ & $3(1)$ & \multirow{2}{*}{$<0.001$} \\
\hline Range & $1-3$ & $1-4$ & \\
\hline
\end{tabular}

There a statistically significant decrease of median in dexmedetomidine group compared to magnesium group according to facial grimace (Table 6).

Table (6): Comparison between Dexmedetomidine Group and Magnesium Group according to facial grimace

\begin{tabular}{|c|c|c|c|}
\hline \begin{tabular}{|ll} 
Facial grimace & Groups \\
\end{tabular} & $\begin{array}{l}\text { Dexmedetomidine } \\
\text { Group }(n=30)\end{array}$ & $\begin{array}{c}\text { Magnesium } \\
\text { Group }(n=30)\end{array}$ & p-value \\
\hline No grimace & $6(20.0 \%)$ & $0(0.0 \%)$ & \multirow{6}{*}{$<0.001$} \\
\hline Minimal grimace & $13(43.3 \%)$ & $3(10.0 \%)$ & \\
\hline Mild grimace & $10(33.3 \%)$ & $10(33.3 \%)$ & \\
\hline Moderate grimace & $1(3.3 \%)$ & $17(56.7 \%)$ & \\
\hline Severe grimace & $0(0 \%)$ & $0(0 \%)$ & \\
\hline Very severe grimace & $0(0 \%)$ & $0(0 \%)$ & \\
\hline Median $(I Q R)$ & $2(1)$ & $4(1)$ & \multirow{2}{*}{$<0.001$} \\
\hline Range & $1-4$ & $2-4$ & \\
\hline
\end{tabular}


There was statistically significant difference between 2 groups according to intubation (Table 7).

Table (7): Comparison between Dexmedetomidine Group and Magnesium Group according to intubation time

\begin{tabular}{|l|c|c|c|}
\hline Intubation time Groups & $\begin{array}{c}\text { Dexmedetomidine } \\
\text { Group }(\mathbf{n}=\mathbf{3 0})\end{array}$ & $\begin{array}{c}\text { Magnesium } \\
\text { Group }(\mathbf{n}=\mathbf{3 0})\end{array}$ & p-value \\
\cline { 1 - 3 } Mean \pm SD & $7.07 \pm 0.29$ & $7.40 \pm 0.36$ & \multirow{2}{*}{$<0.001$} \\
\hline Range & $6.5-7.5$ & $7-8$ & \\
\hline
\end{tabular}

There was no statistically significant difference between 2 groups according to SPO2\% (Table 8).

Table (8): Comparison between Dexmedetomidine Group and Magnesium Group according to SPO2\%

\begin{tabular}{|c|c|c|c|}
\hline SPO2\% $\quad$ Groups & $\begin{array}{l}\text { Dexmedetomidine } \\
\text { Group }(\mathbf{n}=\mathbf{3 0})\end{array}$ & $\begin{array}{c}\text { Magnesium } \\
\text { Group }(n=30)\end{array}$ & $\begin{array}{c}\text { p- } \\
\text { value }\end{array}$ \\
\hline \multicolumn{4}{|l|}{ Baseline } \\
\hline Mean \pm SD & $96.63 \pm 0.56$ & $96.73 \pm 0.52$ & \multirow{2}{*}{0.475} \\
\hline Range & 96-98 & $96-98$ & \\
\hline \multicolumn{4}{|l|}{ At $3 \mathrm{~m}$ after sedation } \\
\hline Mean \pm SD & $95.67 \pm 0.48$ & $95.50 \pm 0.51$ & \multirow{2}{*}{0.197} \\
\hline Range & $95-96$ & $95-96$ & \\
\hline \multicolumn{4}{|l|}{ After advancement ETT } \\
\hline Mean \pm SD & $97.93 \pm 0.45$ & $97.87 \pm 0.57$ & \multirow{2}{*}{0.617} \\
\hline Range & $97-99$ & $97-99$ & \\
\hline \multicolumn{4}{|l|}{ At $3 \mathrm{~m}$ after intubation } \\
\hline Mean \pm SD & $99.13 \pm 0.45$ & $99.27 \pm 0.45$ & \multirow{2}{*}{0.233} \\
\hline Range & $98-100$ & $99-100$ & \\
\hline
\end{tabular}

There was no statistically significant difference between 2 groups according to intubation attempts (Table 9).

Table (9): Comparison between Dexmedetomidine Group and Magnesium Group according to intubation attempts

\begin{tabular}{|c|c|c|c|}
\hline $\begin{array}{ll}\text { Intubation attempts } & \text { Groups } \\
\end{array}$ & $\begin{array}{l}\text { Dexmedetomidine } \\
\text { Group }(\mathbf{n}=\mathbf{3 0})\end{array}$ & $\begin{array}{c}\text { Magnesium } \\
\text { Group }(n=30)\end{array}$ & $\begin{array}{c}\text { p- } \\
\text { value }\end{array}$ \\
\hline One attempts & $20(66.7 \%)$ & $18(60.0 \%)$ & \multirow{2}{*}{0.592} \\
\hline Two attempts & $10(33.3 \%)$ & $12(40.0 \%)$ & \\
\hline
\end{tabular}

\section{DISCUSSION}

The current study was conducted on controlled hypertensive patients with anticipated difficult airway undergoing elective surgery to compare the effects of dexmedetomidine and magnesium sulphate as regards sedative effects, hemodynamics, hypoxic episodes as well as intubation time and intubation attempts during awake fiberoptic intubation.

The study's findings indicated that dexmedetomidine provided satisfactory 
intubating conditions for awake fiberoptic intubation with minimal adverse effects and better patient satisfaction.

The study showed that all patients in dexmedetomidine group achieved Ramsay sedation score (RSS) $\geq 2$ with significantly higher scores of RSS in dexmedetomidine group, while high percentage of patients in magnesium sulphate group failed to reach $\mathrm{RSS} \geq 2$ and required additional sedative in the form of propofol $(50 \mathrm{mg})$.

In our study, satisfactory intubating conditions (facial grimace and coughing) were found in dexmedetomidine group, with better tolerance and less facial grimace and less coughing in dexmedetomidine group, than magnesium group.

Hale et al. (2012) found that in hypertensive patients, administration of dexmedetomidine before anesthesia induction blunted the hemodynamic response to tracheal intubation with significant decrease of blood pressure which is consistent with our results.

Sezen et al. (2014) reported that, in the hypertensive patients, dexmedetomidine premedication as sedative provides better hemodynamic stability compared with midazolam with significant decrease of blood pressure and heart rate which are the same results of our study. Also, Kanchan et al. (2016) found that infusion of dexmedetomidine in hypertensive patients attenuated the sympathetic stress response better than fentanyl and provided stable intraoperative hemodynamics, decreased heart rate and mean blood pressure which are consistent with our study.
Chan and Miwoon (2017) reported that in elderly hypertensive patients on treatment a single preanesthetic dose of dexmedetomidine $\quad(0.5 \mu \mathrm{g} / \mathrm{kg}) \quad$ was effectively sedative and suppressed the hemodynamic responses to endotracheal intubation with significant decrease of blood pressure and heart rate which are the same results of our study but they used smaller dose than our study dose which may be due to their study was only on elderly patients $>65$ years old.

Pooja et al. (2016) found that Dexmedetomidine provides optimum sedation without compromising airway or hemodynamic instability with better patient tolerance and satisfaction for awake fiberoptic intubation. It also preserves patient arousability for the postintubation neurological assessment which is correlated with results of our study.

Rong et al. (2013) found that both dexmedetomidine and remifentanil were effective as sedatives in patients undergoing awake fiberoptic nasotracheal intubation. Compared with remifentanil, dexmedetomidine offered better endoscopy scores, lower recall of intubation, and greater patient satisfaction, with minor hemodynamic side effects which is correlated with results of our study.

Chopra et al. (2016) and Niogyi et al. (2017) found that dexmedetomidine infusion provided optimum level of sedation with favorable hemodynamics and no hypoxic episodes when compared to saline infusion. A decreased need of midazolam in dexmedetomidine group to achieve RSS $\geq 2$ prior to intubation was observed in the Chopra study, while none of the patients receiving dexmedetomidine 
in the Niogyi study required supplementary fentanyl as opposed to $60 \%$ of the patients in the placebo group.

Chu et al. (2010) and Mondal et al. (2015) found better intubating conditions and hemodynamics stability in dexmedetomidine group which is consistent with our study outcomes. In the Mondal study all patients achieved RSS $\geq$ 2 with a higher score in dexmedetomidine group; however it was associated with hypoxic episodes in both groups with a significantly higher incidence in the fentanyl group which is different with our study, No available researches compared the effects of magnesium sulphate against dexmedetomedine as a single sedative in awake fiberoptic intubation in controlled hypertensive patients. However, Adly et al. (2016) compared the postoperative sedative effect of dexmedetomidine versus magnesium sulphate, both drugs were started prior to induction of general anesthesia and continued as infusions till the end of surgery, both drugs provided sedation but the sedative effect of dexmedetomidine was more than that of magnesium sulphate in the first 8 hours following surgery which is consistent with our study, the difference in the sedative effect of magnesium in comparison to our study may be due to the larger dose used prior to induction $40 \mathrm{mg} / \mathrm{kg}$, and the combined effect of general anesthesia.

Nidhi et al. (2013) reported that Magnesium $30 \mathrm{mg} / \mathrm{kg}$ is the optimum dose to control blood pressure during intubation in hypertensive patients. A further increase in the dose of magnesium may cause significant hypotension and flushing which are the same results of our study when we increased dose of magnesium.

Ghosh et al. (2016) found during comparing the analgesic effects of intravenous dexmedetomidine against magnesium sulphate given as adjuvant prior to spinal anesthesia, that dexmedetomidine provided better sedation than magnesium sulphate, which is consistent with the results of our study.

\section{CONCLUSION}

Dexmedetomidine was effective sedative agent for awake fiberoptic intubation in controlled hypertensive patients when used with "spray as you go technique" for anesthetizing the upper airway in comparison with magnesium sulphate as it allowed better patient tolerance, better patient satisfaction and acceptable sedative level without any respiratory depression or clinically significant hemodynamic compromise, while magnesium sulphate appeared not sufficient as a solo sedative agent and we recommended to use it as adjuvant to other sedatives.

\section{REFERENCES}

1. Adly EM and Kamal AM (2016): Dexmedetomidine versus magnesium sulphate as a co-analgesic in video-assisted thoracoscopy. Int J Original Res., 2:48-57.

2. Chan WL and Miwoon K (2017): Effects of preanesthetic dexmedetomidine on hemodynamic responses to endotracheal intubation in elderly patients undergoing treatment for hypertension: a randomized, double-blinded trial. Korean J Anesthesiol., 70(1):39-45.

3. Chopra P, Dixit MB, Dang A and Gupta V (2016): Dexmedetomidine provides optimum conditions during awake fiberoptic intubation in simulated cervical spine injury patients. J Anaesthesiol Clin Pharmacol; 32:54-8. 
4. Chu KS, Wang FY, Hsu HT, Lu IC, Wang HM and Tsai CJ (2010): The effectiveness of dexmedetomidine infusion for sedating oral cancer patients undergoing awake fibreoptic nasal intubation. Eur J Anaesthesiol., 27:3640.

5. Ghosh R, Pramanick $S$ and Banergee $B$ (2016): Comparative study of postoperative analgesia in dexmedetomidine versus magnesium sulfate pretreated patients undergoing elective infraumbilical surgery under subarachnoid block. Indian J Basic Appl Med Res., 760-70.

6. Hale YU, Esma T Pinar A and Hülya B (2012): The effects of dexmedetomidine on hemodynamic responses to tracheal intubation in hypertensive patients: A comparison with esmolol and sufentanyl. J Res Med Sci, 17(1): 22-31.

7. Hyun-Jung S, Hyo-Seok Na and Sang-Hwan Do (2020): Magnesium and Pain. Nutrients; 12: $2184-8$.

8. Kanchan V, Arumugam $V$ and Prasanna $U$ (2016): Comparison of dexmedetomidine with fentanyl for maintenance of intraoperative hemodynamics in hypertensive patients undergoing major surgery: A randomized controlled trial. Anesth Essays Res., 10(2):332337.

9. Klimov A.A., Malakhova A.A., Kamnev S.A. and Subbotin V.V (2018): Use of predictive EL-Ganzouri Score in evaluation of difficult airway in obese patients. Messenger of Ansthesiology and Resusitation; 15(2):38-44.

10. Mondal S, Ghosh S, Bhattacharya S, Choudhury B, Mallick $S$ and Prasad A (2015): Comparison between dexmedetomidine and fentanyl on intubation conditions during awake fiberoptic bronchoscopy: a randomized double blind prospective study. J Anaesth Clin Pharm., 31:212-6.

11. Nidhi B, Neerja B and Seema $P$ (2013): Minimal effective dose of magnesium sulfate for attenuation of intubation response in hypertensive patients. Journal of Clinical Anesthesia., 25: 92-97.

12. Niyogi S, Basak S, Acharjee $A$ and Chakraborty I (2017): Efficacy of intravenous dexmedetomidine on patient's satisfaction, comfort and sedation during awake fibreoptic intubation in patients with cervical spondylotic myelopathy posted for elective cervical fixation. Indian J Anaesth., 61:137-43.

13. Pooja C, Madhu B, Aashish D and Vibhuti G (2016): Dexmedetomidine provides optimum conditions during awake fiberoptic intubation in simulated cervical spine injury patients. J Anaesthesiol Clin Pharmacol., JanMar; 32(1): 54-58.

14. Rong H, Liu J and Jiang H (2013): Dexmedetomidine versus remifentanil sedation during awake fiberoptic nasotracheal intubation: a double-blinded randomized controlled trial. Journal of Anesthesia., 27: 211-217.

15. Sezen G, Demiraran Y, Iskender A, Erosy O and Ankarali $H$ (2014): Does premedication with dexmedetomidine provide perioperative hemodynamic stability in hypertensive patients? BMC Anesthesiol., 14:113-115.

16. Tsukamoto $M$, Hitosugi $T$ and Yokoyama $T$ (2018): Awake fiberoptic nasotracheal intubation for patients with difficult airway. J Dent Anesth Pain Med., 18(5):301-304.

17. Weerink MAS, Struys MMRF, Hannivoort LN, Barends CR, Absalom AR and Colin P (2017): Clinical pharmacokinetics and pharmacodynamics of dexmedetomidine. Clin Pharmacokinet., 1-21. 
دراسة إستخدام الدكسميدينو ميدين مقارنة بإستخدام سلفات

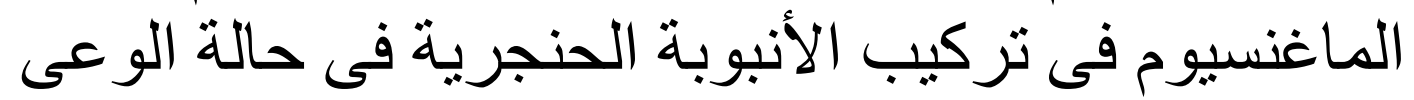

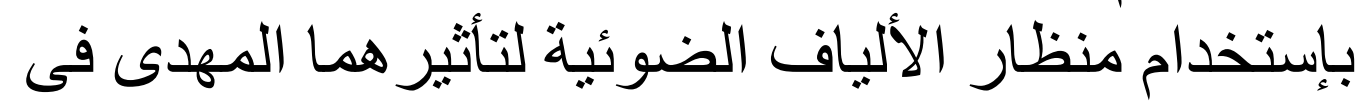

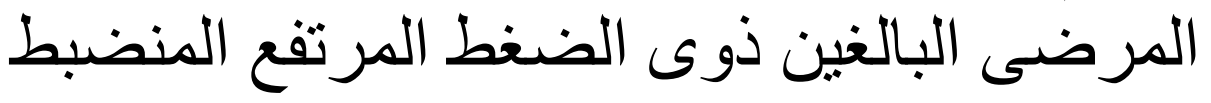
محمد على محمد عبدالعال، جمال فاروق محمد، عمرو سليمان حمروش البع العين قسم التخدير والرعاية المركزة، كلية الطب، جامعة الأزهر

E-mail: $\underline{\text { dr muhammed8632@yahoo.com }}$

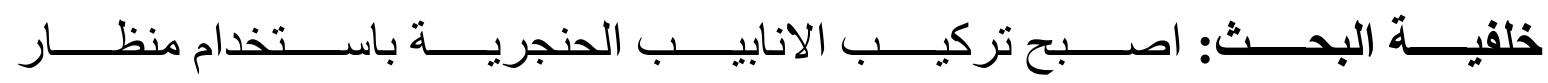

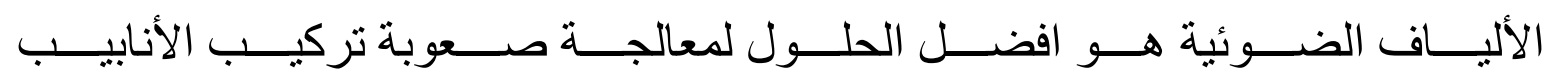

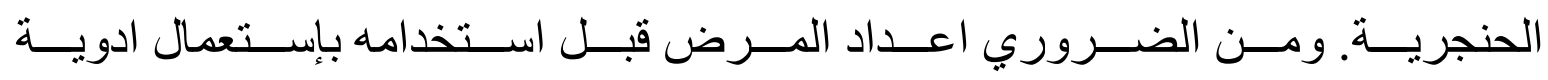

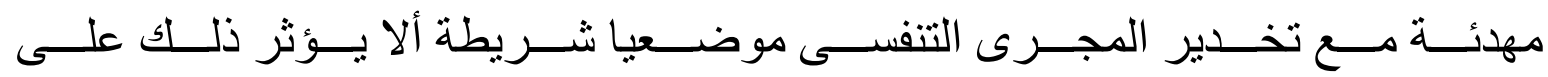

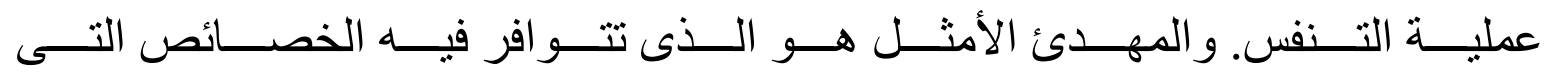

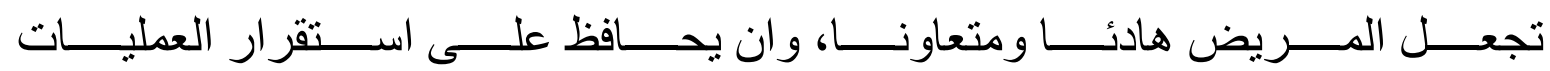

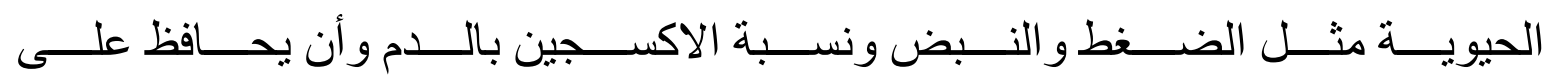
مجرى الهو اء مفتو حا والتنفس مستمر ا بعد إستخدامه.

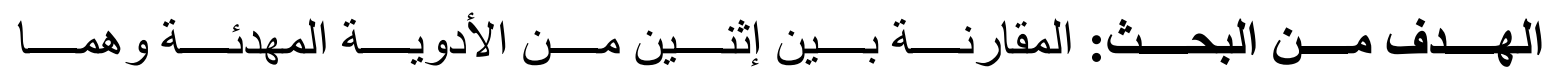

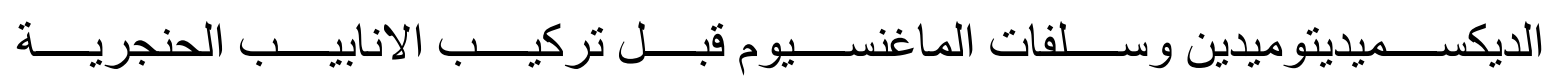
فى حالة الوعى باستخدام منظار الألياف الضوئية.

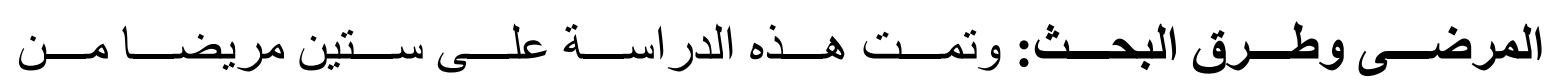

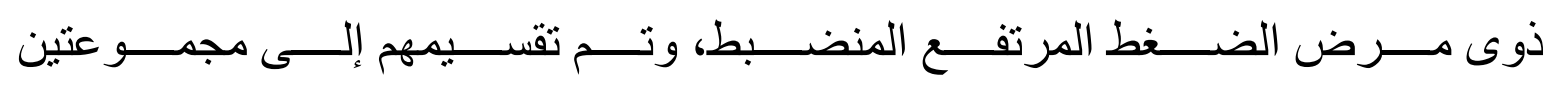

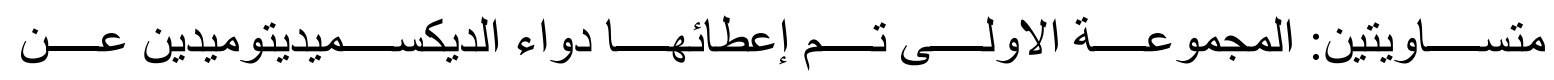

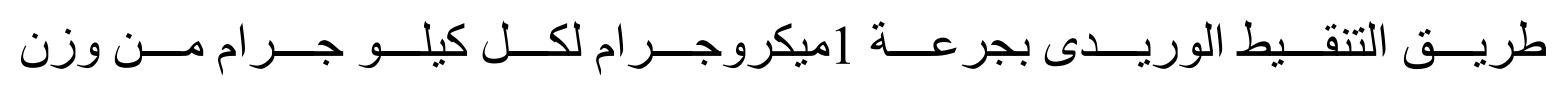

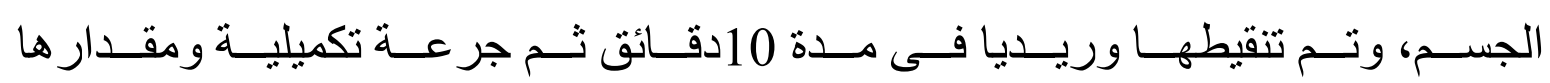

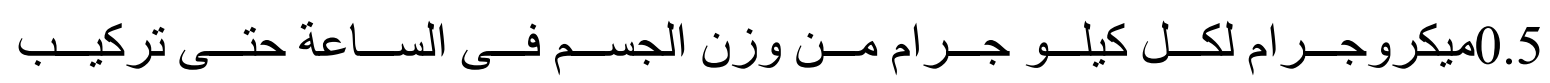




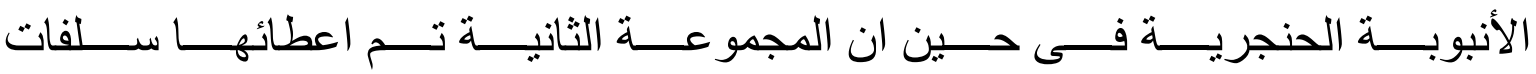

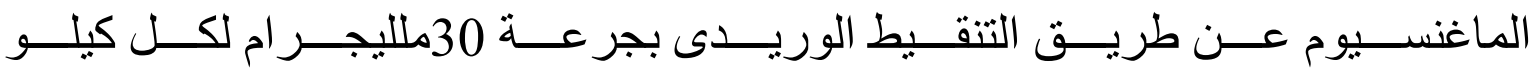

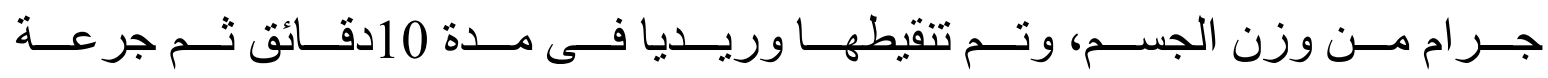

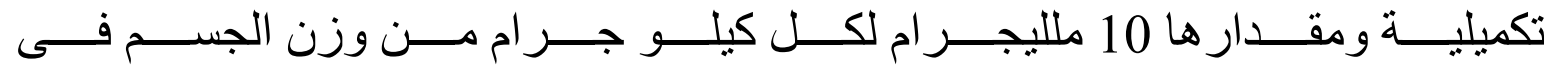

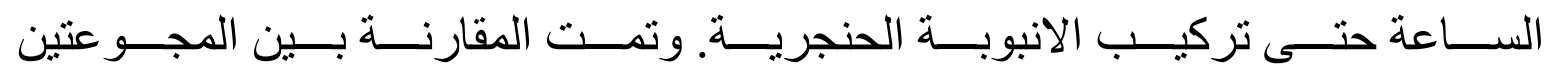
عن طريق أيهما أكثر تهيئة وتأثثير هما على العلامات الحيوية.

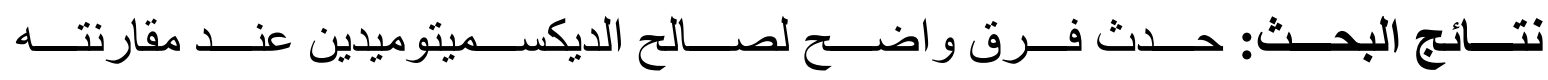

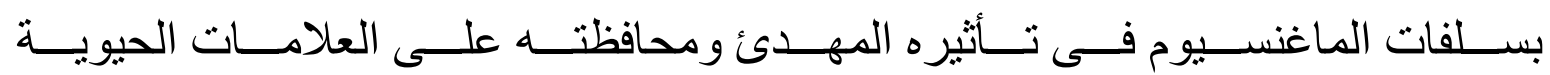

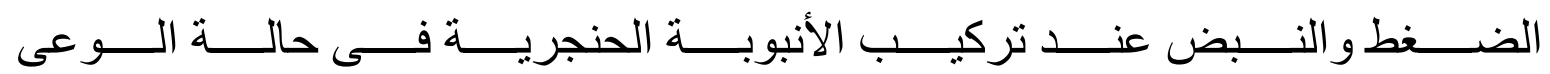
بإستخدام منظار الألياف الضوئية.

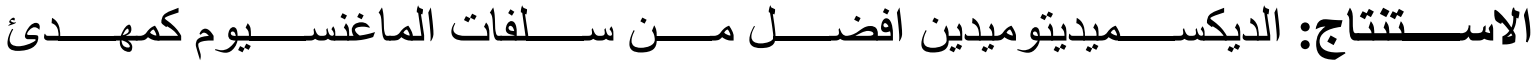

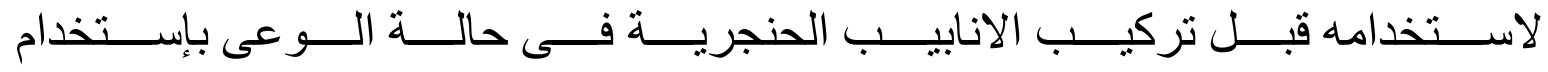

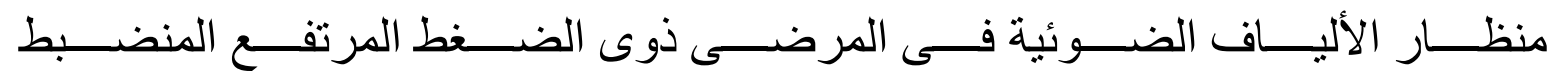

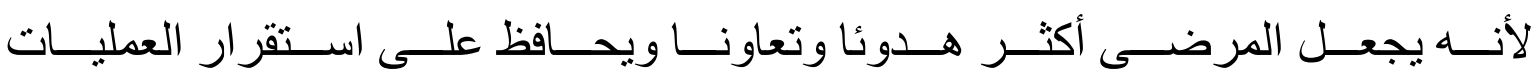
الحيوية.

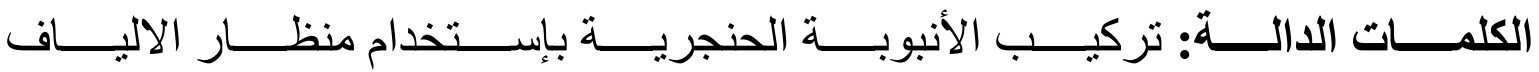
الضوئية، الديكسميتو ميدين، سلفات الماغنسيوم. 